\title{
Midbrain infarct presenting as isolated medial rectus palsy
}

Sir,

A 30-year-old man, labourer by occupation, presented with sudden onset of giddiness followed by diplopia with horizontal separation of images on looking to 
extreme left gaze. On examination, hemodynamics were normal and neurological examination showed right medial rectus palsy [Figure 1]. Magnetic resonance imaging (MRI) of the brain showed a hyperintensity in rostral midbrain in diffusion weighted images [Figure 2] and flair images. He was thoroughly investigated for the causes of young stroke and was found to have dyslipidemia, which was treated with cholesterollowering agents and antiplatelets. The patient received visual tracking eye exercises during his hospital stay and his complaints resolved within three weeks.

Oculomotor nerve has two motor nuclei, the main motor nucleus and the accessory parasymphathetic nucleus. The main oculomotor nucleus which is situated in the anterior part of the gray matter surrounding the cerebral acqueduct of the midbrain at the level of superior colliculus supplies all the extrinsic muscles of the eye except the superior oblique and lateral rectus muscle. It consists of one unpaired central caudal nucleus for

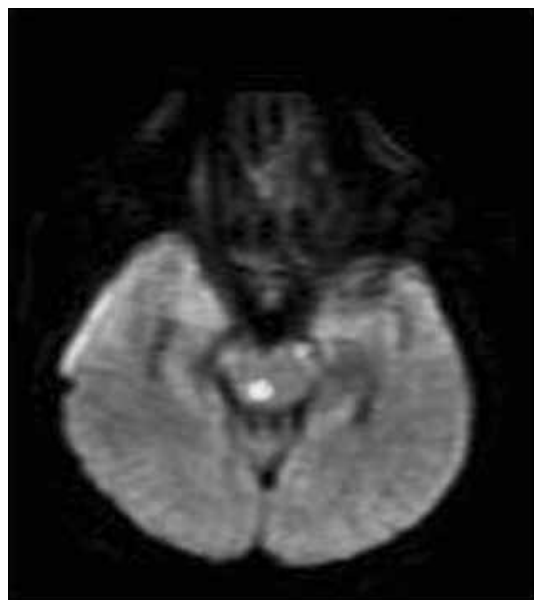

Figure 1: MRI brain - Diffusion weighted image showing hyperintensity in right-sided midbrain situated ventrally
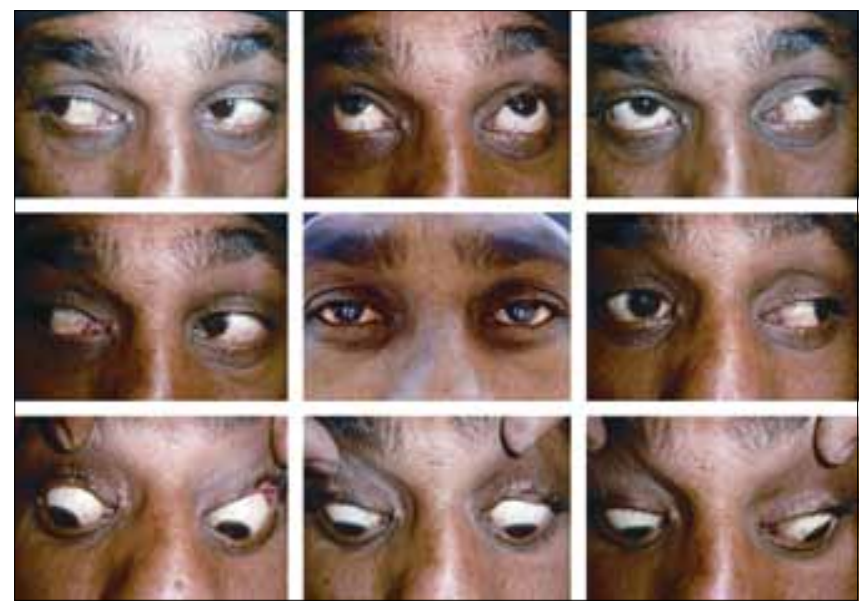

Figure 2: Extraocular movements' examination showing evidence of right medial rectus palsy

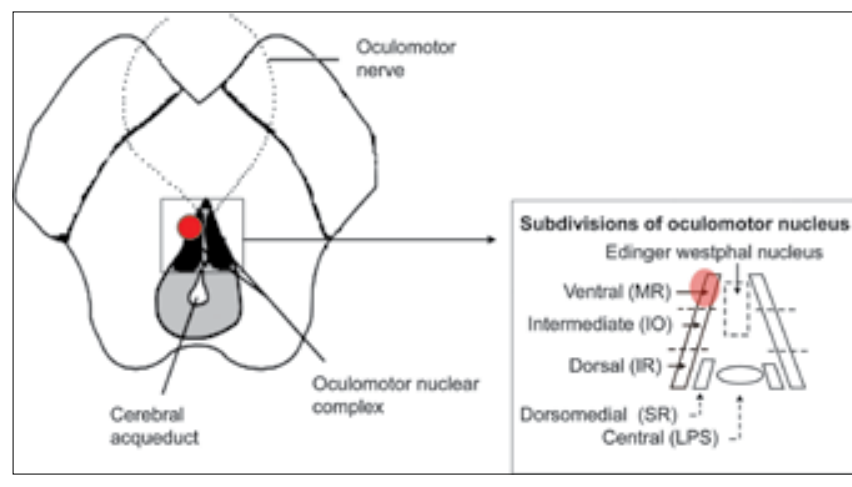

Figure 3: Schematic representation of the midbrain at the superior collicular level with oculomotor nuclear complex and the lesion (marked in red); also shown are the subdivisions of oculomotor nucleus with various subnuclei MR - Medial rectus, 10 - Inferior oblique, IR - Inferior rectus, SR - Superior rectus, LPS - Levator palpebrae superioris

bilateral levator palpebrae superioris and four paired subnuclei. ${ }^{[1]}$ The subnucleus for superior rectus muscle is situated dorsomedially and decussation of the fibers to the superior rectus takes place within the oculomotor nuclear complex; thus, lesions affecting the nucleus may simultaneously involve ipsilater al superior rectus subnuclei as well as crossing fibers resulting in bilateral superior rectus muscle palsy. ${ }^{[2]}$ Ventral to the superior rectus subnuclei lies the subnuclei for ipsilateral inferior rectus followed by intermediate subnuclei for ipsilateral inferior oblique and the most ventrally situated subnuclei is for ipsilateral medial rectus [Figure 3]. Third nerve nuclear lesions cause weakness of bilateral superior rectus muscle ipsilateral inferior oblique, inferior rectus, medial rectus, with bilateral partial ptosis (due to involvement of central caudal subnuclei supplying both levator palpebrae superioris). This is a case of nuclear oculomotor nerve palsy with an unusual presentation due to strategic location of infarct in the rostral midbrain involving the medial rectus subnuclei which is situated most ventrally and can be diagnosed with diffusion weighted imaging (DWI). ${ }^{[3]}$ Unilateral ocular palsy is commonly seen with lesions in the orbit or from muscular diseases and rarely from a third nerve nuclear lesion, though inferior oblique muscle palsy caused by involvement of intermediate subnuclei ${ }^{[4]}$ and isolated inferior rectus palsy due to ipsilateral involvement of dorsally situated subnuclei or fascicular lesions have been described. ${ }^{[5]}$ With use of DWI and other multimodality MRI the probability of picking up midbrain infarcts causing isolated oculomotor palsies have increased.

\section{Simerpreet Bal, Vivek Lal, Dheeraj Khurana, Sudesh Prabhakar}

Department of Neurology, Postgraduate Institute of Medical Education and Research, Chandigarh - 160 012, India. E-mail:vivek144@yahoo.com

DOI: 10.4103/0028-3886.55579 


\section{References}

1. Brazis PW, Masdeu JC, Biller J. Localization in clinical neurology. $3^{\text {rd }}$ ed. Boston, MA: Little, Brown and Company; 1996.

2. Rabadi MH, Beltmann MA. Midbrain infarction presenting isolated medial rectus nuclear palsy. Am J Med 2005;118:836-7.

3. Kwon JH, Kwon SU, Ahn HS, Sung KB, Kim JS. Isolated superior rectus palsy due to contralateral midbrain infarction. Arch Neurol 2003;60:1633-5.

4. Castro O, Johnson LN, Mamourian AC. Isolated inferior oblique paresis from brain-stem infarction. Perspective on oculomotor fascicular organization in the ventral midbrain tegmentum. Arch Neurol 1990;47:235-7.

5. Lee DK, Kim JS. Isolated inferior rectus palsy due to midbrain infaretion detected by diffusion- weighted MRI. Neurology 2006;66:1956-7.

Accepted on 26-02-2009 